\title{
Application of a Simplified Molecular Protocol to Reveal Mixed Infections with Begomoviruses in Cassava
}

\author{
J. P. Busogoro ${ }^{1}$, L. Masquellier ${ }^{1}$, J. Kummert ${ }^{1}$, O. DutrecQ ${ }^{2}$, P. Lepoivre ${ }^{1}$ and M. H. Jijakli ${ }^{1}$ \\ Authors' addresses: ${ }^{1}$ Plant Pathology Unit, Gembloux Agricultural University, Passage des Déportés 2, Gembloux 5030, \\ Belgium; ${ }^{2}$ DNALIS SPRL, spin-off of Gembloux Agricultural University, Rue de la Croix Rouge 20, Gembloux 5032, \\ Belgium (correspondence to J. P. Busogoro. E-mail: jpbusogoro@yahoo.fr) \\ Received April 11, 2007; accepted November 14, 2007
}

Keywords: recombination, African cassava mosaic virus, East African cassava mosaic virus, PCR, Uganda variant

\begin{abstract}
Samples of cassava leaves exhibiting severe symptoms of cassava mosaic disease (CMD) were collected with the PhytoPASS kit in fields surrounding the city of Bujumbura (Burundi). These materials were then sent to Belgium for polymerase chain reaction determination of the CMD begomoviruses inducing the observed symptoms. Different pairs of specific primers were used to amplify DNA sequences specific to African cassava mosaic virus (ACMV), East African cassava mosaic virus (EACMV), East African cassava mosaic Cameroon virus (EACMCV), East African cassava mosaic Malawi virus (EACMMV), East African cassava mosaic Zanzibar virus (EACMZV), the Uganda variant of East African cassava mosaic virus (EACMV-UG) and South African cassava mosaic virus (SACMV). It was revealed that mixed infections were prevailing in the analyzed materials. Most of the samples submitted to this analysis were found to be co-infected by three different begomoviruses (ACMV + EACMV + EACMV-UG). The so revealed mixed infections could explain the high severity of CMD symptoms noticed on cassava in the region of Bujumbura while the diversity within the CMD causal agents illustrates the importance to take this parameter into consideration for a successful use of plant genetic resistance to control the disease.
\end{abstract}

\section{Introduction}

Cassava (Manihot esculenta), the only species cultivated as food crop in its genus (Fauquet and Fargette, 1990) is considered as the most important crop grown in Africa (Briddon et al., 2004). By providing food to over 500 million people around the world (Varma and Malathi, 2003), this tuber crop is occupying the third most important place after cereals and grain legumes. Economic and social importance of cassava is still increasing significantly throughout Africa. Nowadays, cassava is cultivated in different African ecological conditions ranging from the humid regions of Central Africa and the Guinean Golf to semi-arid areas of the Sahelian countries and in South-Eastern countries. Ability of this species to tolerate drought and degraded soils (Olsen, 2004) constitutes a determinant parameter for its high importance. Considering the continuous increases in human population and pressure on available land and the decline of soil fertility (Thresh and Cooter, 2005), it appears that cassava would continue to play a major role for food security in Sub-Saharan Africa because of its ability to generate acceptable production levels in marginal conditions.

Despite the importance of the crop, cassava production in Africa is seriously threatened by the cassava mosaic disease (CMD) which is considered as the most important disease in Sub-Saharan Africa (Ogbe et al., 2003). This disease caused by whitefly-borne viruses belonging to the genus Begomovirus (family Geminiviridae) occurs in all cassava-producing areas in Africa, India and Sri-Lanka (Owor et al., 2004) and induces high levels of yield losses particularly in Africa. The global level of losses due to CMD throughout Africa was estimated to reach $19.6-27.8 \%$ of the actual production (Zhang et al., 2005).

The begomoviruses causing CMD are vector-transmitted by whitefly Bemisia tabaci (Fargette and Vié, 1995), while the use of cuttings from infected plants constitutes another way of widespread disease. Infected plants can be visually recognized by appearance of symptoms characterized by development of leaf mosaic which is generally more severe on young plants than on old ones (Fauquet and Fargette, 1990). Other morphological modifications ranging from leaf distortion to stunted growth of plants are associated with this disease (Varma and Malathi, 2003). Severity of CMD symptoms is variable according to different parameters like host genotype, season, stage of crop growth and virus strain or species involved in the disease. 
Begomovirus species or strain is the determinant for symptom severity and consequently for the importance of yield losses. Therefore, it would be interesting to take into account the diversity of begomoviruses inducing CMD in cassava. In that context, it was demonstrated that different Begomovirus species are responsible of CMD development (Zhou et al., 1997; Fondong et al., 2000; Maruthi et al., 2002). Zhou et al. (1997) reported the existence of three different species (i) African cassava mosaic virus (ACMV), (ii) East African cassava mosaic virus (EACMV) and (iii) Indian cassava mosaic virus (ICMV) with different geographical localization. For that, it was considered that ACMV and EACMV are occurring respectively to the west and east of the African Rift valley, while ICMV is found in India and Sri Lanka. More recent works revealed occurrence of a higher diversity of CMD inducing species comprising ACMV, EACMV, East African cassava mosaic Cameroon virus (EACMCV), East African cassava mosaic Malawi virus (EACMMV), East African cassava mosaic Zanzibar virus (EACMZV) and South African cassava mosaic virus (SACMV) (Ndunguru et al., 2005). The previously supposed restriction of geographical localization between EACMV and ACMV in Africa is not verified because isolates of ACMV are found in Eastern countries while EACMV isolates are detected in west Africa (Ranomenjanahary et al., 2002; Ogbe et al., 2006).

Molecular characterization of the CMD agents revealed the possibility that new causal agents can arise from a recombination phenomenon between the pre-existing viruses. The Uganda variant of EACMV (EACMV-UG or UgV), whose occurrence was associated with severe epidemic of CMD in Uganda (Harrisson et al., 1997; Pita et al., 2001) constitutes a typical illustration of new begomovirus appearance due to recombination between different pre-existing CMD causal agents (Zhou et al., 1997).

Although the Uganda variant is associated with severe pandemic of cassava mosaic disease, different studies showed that plants showing severe CMD symptoms are dually infected by both ACMV and the Uganda variant (Varma and Malathi, 2003; Colvin et al., 2004; Thresh and Cooter, 2005). Fields affected by the severe mosaic produce little or no yield and this situation has led to huge economic losses with dramatic consequences of food shortages and famine in some areas (Varma and Malathi, 2003). Through a survey study conducted in Nigeria (Ogbe et al., 2006), a large distribution of ACMV and EACMV in the country was shown, with a proportion of $24.4 \%$ of mixed infections by these two viruses. Analyses carried out on cassava materials collected from Burundi in 2003 to assess the status of CMD allowed revealing of the presence of different begomoviruses including EACMV-UG, ACMV and EACMV with some cases of mixed infections containing ACMV and EACMVUG (Bigirimana et al., 2004).

The purpose of this work was to investigate the potential importance of mixed infections in cassava plants showing severe CMD symptoms in the region of Bujumbura. A simplified sampling protocol associated to PCR detection of CMD agents was used to identify the begomoviruses associated with the severe symptoms of the disease.

\section{Materials and Methods \\ Sampling of cassava materials}

Previous works have shown the ability to use the PhytoPASS (DNAlis sprl, Gembloux, Belgium) system to sample cassava in view of CMD begomovirus molecular detection even after 15 days of sample storage at room temperature (data not shown). For the present work, samples were collected from seven plants presenting severe CMD symptoms in cassava fields in the region of Bujumbura. The PhytoPASS sampling kit (DNAlis sprl) was used to collect, store and transport the cassava-sampled materials. The sampling was performed by scraping the PhytoPASS abrasive membrane on the leaf surface of the selected plants. After sampling, each of the seven PhytoPASS was annotated and placed individually in a paper pouch. Transport to the laboratory (Gembloux Agricultural University, Gembloux, Belgium) for molecular analyses was performed easily in luggage at ambient temperature.

\section{Suspending the sampled cassava materials}

Once the seven PhytoPASS were delivered to the Plant Pathology laboratory in Gembloux (Belgium), the abrasive membrane covered with fragments of cassava tissues was detached from the PhytoPASS box and then introduced in a $10-\mathrm{ml}$ glass tube containing $1 \mathrm{ml}$ of cold $\left(4^{\circ} \mathrm{C}\right) \mathrm{KAJI}$ extraction buffer (DNAlis sprl). A rapid agitation with vortex was performed to recover the plant tissues' fragments in a suspension which was kept on ice. The suspension thus obtained constituted the primary crude extract which was diluted 100 times in distilled water before PCR analysis.

\section{Molecular detection of CMD begomoviruses}

The seven samples were submitted for molecular detection of CMD agents by PCR reactions in which specific primers (Table 1) that could detect ACMV, EACMV, EACMCV, EACMMV, EACMZV, EACMV-UG and SACMV, respectively were used. Positive controls consisting of extracts of infected cassava plants growing under greenhouse conditions (for the viruses ACMV, EACMV and EACMV-UG) or in purified DNA provided by (DSMZ, Braunschweig, Germany) (DSMZ PV-0872 for EACMCV and DSMZ PV-0845 for EACMZV) were used to control efficiency of the PCR reactions. No positive controls were available for the viruses EACMMV and SACMV. The PCR amplification was achieved with a PTC 200 thermocycler (Biozym, Landgraaf, the Netherlands) in a final volume of $50 \mu \mathrm{l}$ containing $5 \mu \mathrm{l}$ of the $10 \times$ concentrated PCR reaction buffer (Roche, Mannheim, Germany), $200 \mu \mathrm{M}$ of each dNTP, $0.5 \mu \mathrm{M}$ of each primer, $0.2 \mu \mathrm{l}$ of the Taq Polymerase solution $(5 \mathrm{U} / \mu \mathrm{l})$ and $5 \mu \mathrm{l}$ of the $100 \times$ diluted plant crude extract 
Table 1

Sequences of primers used to detect CMD begomoviruses in plant tissues collected with the PhytoPASS system in Burundi

\begin{tabular}{|c|c|c|}
\hline CMD virus & Primer name and sequence $\left(5^{\prime}-3^{\prime}\right)$ & Reference \\
\hline \multirow[t]{2}{*}{ ACMV } & ACMV-AL1F: GCG GAA TCC CTA ACA TTA TC & Maruthi et al. (2002) \\
\hline & ACMV-AR0/R: GCT CGT ATG TAT CCT CTA AGG CCT G & Maruthi et al. (2002) \\
\hline \multirow[t]{2}{*}{ EACMV } & VNF033: CCG TAA CTT GGA GAG TGT TTA & Fondong et al. (2000) \\
\hline & VNF034: GGA TGA GGA AAA GAA TCA GTC & Fondong et al. (2000) \\
\hline \multirow[t]{2}{*}{ EACMCV } & VNF031: GGA TAC AGA TAG GGT TCC CAC & Fondong et al. (2000) \\
\hline & VNF032: GAC GAG GAC AAG AAT TCC ATT & Fondong et al. (2000) \\
\hline \multirow[t]{2}{*}{ EACMMV } & MAL-L3/F: TAC GCA TGC CTC TAA TCC AG & Zhou et al. (1998) \\
\hline & MAL-L1/R: TTC CGC CAC AAC CTT ATG TA & Zhou et al. (1998) \\
\hline \multirow[t]{2}{*}{ EACMZV } & Ca122fl A Bams: GAT CCA TTG TTA AAC GAT TTC CCT GAA & Were et al. (2004) \\
\hline & Ca122fl A Bamc: CCA CAT GTT GAC GCG CTC CAC TAC TT & Were et al. (2004) \\
\hline \multirow[t]{2}{*}{ EACMV-UG } & UV-AL1/F1: TGT CTT CTG GGA CTT GTG TG & Maruthi et al. (2002) \\
\hline & ACMV-CP/R3: TGC CTC CTG ATG ATT ATA TGT C & Maruthi et al. (2002) \\
\hline \multirow[t]{2}{*}{ SACMV } & PN-REPC2611: AAT GAA TTC CTC ACG TAT CCG & Makwarela et al. (2006) \\
\hline & PN-REPV1990: CGA TGA GGA TCC TAC TCG G & Makwarela et al. (2006) \\
\hline
\end{tabular}

CMD, cassava mosaic disease; ACMV, African cassava mosaic virus; EACMV, East African cassava mosaic virus; EACMCV, East African cassava mosaic Cameroon virus; EACMMV, East African cassava mosaic Malawi virus; EACMZV, East African cassava mosaic Zanzibar virus; EACMV-UG, the Uganda variant of East African cassava mosaic virus and SACMV, South African cassava mosaic virus.

suspension. Amplification conditions included a first PCR cycle comprising denaturation at $94^{\circ} \mathrm{C}$ for $5 \mathrm{~min}$, annealing of primers at $52^{\circ} \mathrm{C}$ for 1 min and elongation at $72^{\circ} \mathrm{C}$ for $2 \mathrm{~min}$. This initial amplification cycle was followed by 35 cycles of $1 \mathrm{~min}$ at $94^{\circ} \mathrm{C}, 1 \mathrm{~min}$ at $52^{\circ} \mathrm{C}$ and $2 \mathrm{~min}$ at $72^{\circ} \mathrm{C}$. At the end of the reaction, a final elongation step was achieved at $72^{\circ} \mathrm{C}$ for $10 \mathrm{~min}$. PCR products were separated by electrophoresis in a $1 \%$ agarose gel containing ethidium bromide $(1 \mu \mathrm{g} / 10 \mathrm{ml})$ under a constant current of $120 \mathrm{~mA}$. This migration was followed by visualization of the amplified bands under UV light.

\section{Results}

Quality of the sampled materials at delivery in Belgium

The series of seven plants showing severe symptoms of CMD were numbered from 1 to 7 . The different steps leading to plant tissues recovery to prepare PCR template from the materials sampled with the PhytoPASS are shown on the picture (Fig. 1). It appeared that plant tissues collected with the PhytoPASS system remained green (Fig. 1a) until they were received in the laboratory, in spite of transport and storage at ambient temperature during 3 weeks.

Application of the extraction protocol in the KAJI buffer was achieved without any particular difficulty (Figs $1 \mathrm{~b}$ and 1c) related to the long period (3 weeks) separating collection of samples and their suspension in the extraction buffer. A suspension of plant extracts characterized by a green colour (Fig. 1d) was thus obtained after agitation of the PhytoPASS membranes in the extraction buffer.

\section{Detection of the begomoviruses in the cassava samples}

The cassava materials collected by PhytoPASS (DNA1is sprl) were used as a template for PCR amplification to detect CMD begomoviruses present in each sample (plant with severe symptoms). Different amplification profiles were obtained for the seven samples analyzed by using the primer pairs relative to ACMV, EACMV,
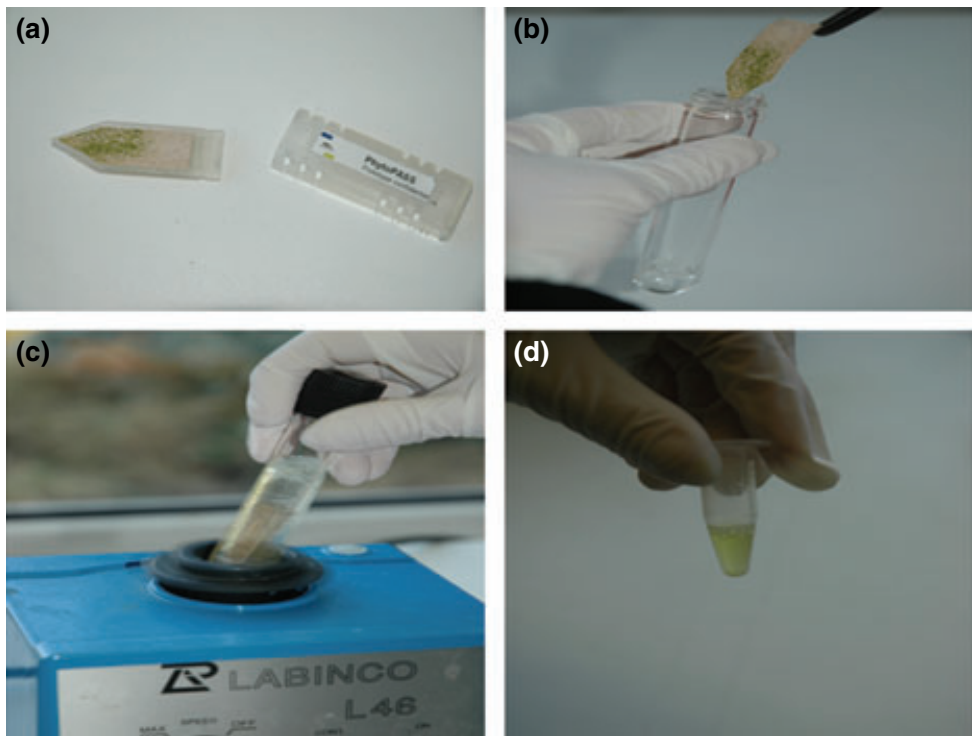

Fig. 1 Aspect of the cassava tissues collected with PhytoPASS and their suspension in the KAJI extraction buffer. (a) Green colour of the plant tissue fragments observed 3 weeks after their collection; (b) introduction of the membrane into a glass tube containing KAJI extraction buffer; (c) agitation process performed to detach the plant tissue fragments; (d) green aspect of the final suspension 
Table 2

CMD begomoviruses detection and typing in cassava samples collected in Burundi with the PhytoPASS system

\begin{tabular}{lccccccc}
\hline & \multicolumn{7}{c}{ Number of the analysed cassava sample } \\
\cline { 2 - 8 } CMD agent & Sample 1 & Sample 2 & Sample 3 & Sample 4 & Sample 5 & Sample 6 & Sample 7 \\
\hline ACMV & 1 & 1 & 1 & 1 & 1 & 1 & 1 \\
EACMV & 1 & 1 & 1 & 1 & 1 & 0 & 1 \\
EACMCV & 0 & 0 & 0 & 0 & 0 & 0 & 0 \\
EACMMV & 0 & 0 & 0 & 0 & 0 & 0 & 0 \\
EACMZV & 0 & 0 & 0 & 0 & 0 & 0 & 0 \\
EACMV-UG & 1 & 1 & 1 & 0 & 1 & 1 & 1 \\
SACMV & 0 & 0 & 0 & 0 & 0 & 0 & 0 \\
\hline
\end{tabular}

CMD, cassava mosaic disease; ACMV, African cassava mosaic virus; EACMV, East African cassava mosaic virus; EACMCV, East African cassava mosaic Cameroon virus; EACMMV, East African cassava mosaic Malawi virus; EACMZV, East African cassava mosaic Zanzibar virus; EACMV-UG, the Uganda variant of East African cassava mosaic virus and SACMV, South African cassava mosaic virus.

1: the PCR reaction was positive, revealing presence of the expected amplification products, 0 : the PCR reaction was negative, revealing absence of amplification product.
EACMCV, EACMMV, EACMZV, EACMV-UG and SACMV, respectively (Table 2). The generated amplification profiles did not reveal presence of EACMCV, EACMMV, EACMZV and SACMV within the analyzed samples. In contrast, the detection tests showed that presence of the viruses ACMV, EACMV and EACMV-UG was detectable within the cassava samples collected in Burundi. More specifically, infections with ACMV were revealed in all the sampled cassava plants (Fig. 2). Presence of the two other viruses (EACMV and EACMV-UG) which were found in the analyzed samples was revealed in six of the seven cassava samples (Figs 3 and 4).

Based on the amplification profile generated through the use of the different primer pairs, it became evident that mixed infections occurred in all the seven cassava plants sampled on the basis of CMD severe symptoms. For the sample number four, dual infection involving ACMV and EACMV was revealed while for the sample number six, a dual infection with ACMV and EACMV-UG was observed. All the remaining five samples were tested positive for mixed infections involving ACMV + EACMV + EACMV-UG. To the best of our knowledge, it is the first time that mixed infections involving three different CMD viruses

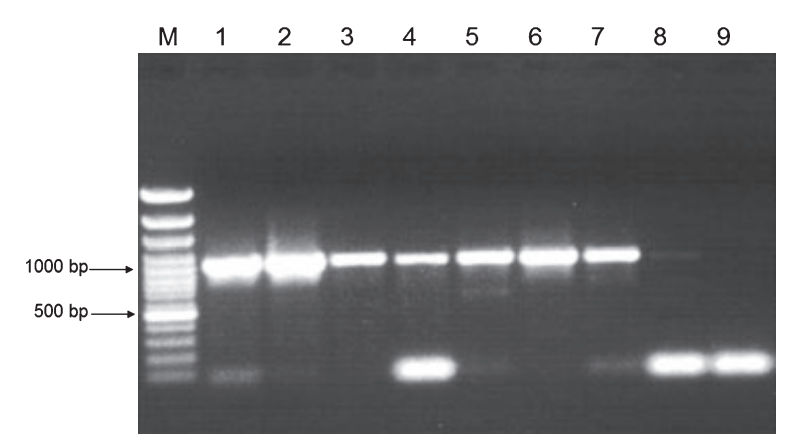

Fig. 2 Molecular detection of African cassava mosaic virus (ACMV) in the cassava samples collected in Burundi using the PhytoPASS system. Lane M: 100-bp ladder; lanes 1-7: samples collected from the seven cassava plants showing severe cassava mosaic disease symptoms; lane 8: positive control (a greenhouse cassava plant previously proved to be infected by ACMV); lane 9: negative control (distilled water instead of cassava samples)

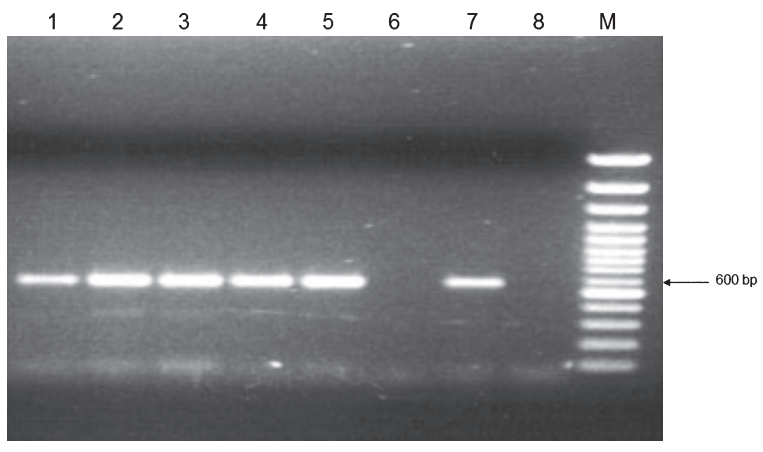

Fig. 3 Molecular detection of East African cassava mosaic virus in the cassava samples collected in Burundi using the PhytoPASS system. Lanes 1-7: samples collected from seven cassava plants showing severe cassava mosaic disease symptoms; lane 8: negative control (distilled water instead of cassava samples); lane M: 100-bp ladder

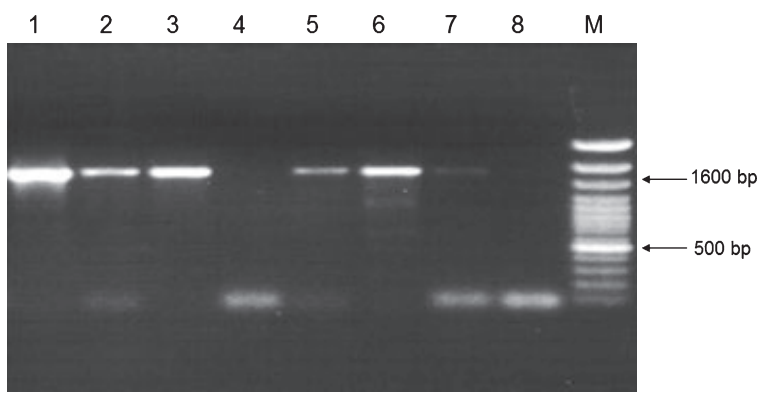

Fig. 4 Molecular detection of Uganda variant of East African cassava mosaic virus in the cassava samples collected in Burundi using the PhytoPASS system. Lanes 1-7: samples collected from seven cassava plants showing severe cassava mosaic disease symptoms; lane 8 : negative control (distilled water instead of cassava samples); lane M: 100-bp ladder

are detected in cassava. Given that presence of severe CMD symptoms constituted a basic criterion for the selection of cassava plants to be sampled for this analysis and that mixed infections were found in all the seven plants, the revealed mixed infections could be considered as being responsible in the development of severe symptoms. In addition, the presence of three different begomoviruses in the restricted region of Bujumbura highlights the potential important level of diversity within CMD causal agents in the country. 


\section{Discussion}

In the present study, molecular analyses were carried out to detect a series of seven different begomoviruses causing CMD. The viruses EACMCV, EACMMV, EACMZV and SACMV were not detected in the samples collected from Burundi while the three other viruses (ACMV, EACMV and EACMV-UG) were detected within the same samples. For each of the three detected viruses, the amplified DNA fragment was of the same size as that obtained with the corresponding positive control.

Prevalence of diversity in CMD begomoviruses in Burundi's cassava fields had been reported from a study conducted in 2003 (Bigirimana et al., 2004). This previous survey revealed the occurrence of mixed infections with ACMV + EACMV-UG in a low proportion of the studied sites. However, the presence of the EACMV-UG was not revealed in the region of Bujumbura during this investigation.

Results generated through the present study revealed infections with EACMV-UG in six of the seven analysed samples, confirming thus the rapid spread of the Uganda variant which is now present in the region of Bujumbura. It is important to remind that the sampling operation had been performed only on plants showing severe symptoms of CMD. Achievement of molecular detection using primer pairs specific to different CMD begomoviruses showed that all the sampled cassava plants contained mixed infections. This observation is in agreement with the previously established knowledge considering that mixed infections with CMD begomoviruses result in more severe symptoms (Fondong et al., 2000; Colvin et al., 2004; Ariyo et al., 2005; Ogbe et al., 2006). All these previous works reported occurrence of severe symptoms of CMD associated to mixed infections involving co-infection with two different begomoviruses. Dual infections involving ACMV and EACMV-UG were shown to be prevalent in areas affected by the severe CMD pandemic which began in Uganda and rapidly spread to other countries in the region (Thresh and Cooter, 2005). Plants showing severe CMD symptoms in the pandemic area were infected by both ACMV and EACMV-UG whereas plants with moderate symptoms were infected by either ACMV or EACMV-UG alone (Colvin et al., 2004). On this basis, it becomes evident that although the Uganda variant (EACMV$\mathrm{UG}$ ) is commonly considered to be the main cause of the severe CMD pandemic spreading in Eastern and central Africa, its presence in mixed infections with ACMV is a more determinant condition for development of severe CMD symptoms.

The present work revealed for the first time occurrence of co-infections with three different begomoviruses (ACMV + EACMV + EACMV-UG) in cassava plants showing severe CMD symptoms. Triple infections were the most represented in the sampled plant materials while dual infections (ACMV + EACMV and ACMV + EACMV-UG) were present in each case of the seven analyzed materials. Occurrence of mixed infections containing three begomoviruses in plants was already described for species like tomato in Nicaragua (Ala-Poikela et al., 2005). Multiple infections with begomoviruses within a same plant can drive to important evolution of the virus species and strains. In fact, the recombination phenomenon is considered common between begomoviruses (Ribeiro et al., 2003) and can lead to emergence of more virulent or better-adapted viruses in specific host plants. In the case of cassava, occurrence of different CMD begomoviruses within the same producing area constitutes a great potential risk to assist the development of mixed infections as the viruses can be transmitted between plants by the whitefly vectors.

The present work revealed diversity among the CMD agents prevailing in the region of Bujumbura. These findings are correlated with the previous observations which had revealed the existence of several CMD agents in the country (Bigirimana et al., 2004). Presence of mixed infections containing in six of the seven analysed samples, three different begomoviruses could lead to increase the existing diversity through the recombination phenomenon. This aspect of the cassava-CMD pathosystem has to be taken into consideration for a successful implementation of plant genetic resistance to control CMD.

\section{Acknowledgements}

Our warmest thanks go to Gordien Niyongabo, a scientist working at the University of Burundi, Agricultural sciences faculty, for his determined help in identification of cassava fields to be sampled.

\section{References}

Ala-Poikela M, Svensson E, Rojas A et al. (2005) Genetic diversity and mixed infections of begomoviruses infecting tomato, pepper and cucurbit crops in Nicaragua. Plant Pathol 54:448-459.

Ariyo OA, Koerbler M, Dixon AGO, Atiri GI, Winter S. (2005) Molecular variability and distribution of Cassava Mosaic Begomoviruses in Nigeria. J Phytopathol 153:226-231.

Bigirimana S, Barumbanze P, Obonyo R, Legg JP. (2004) First evidence for the spread of East African cassava mosaic virus-Uganda (EACMV-UG) and the pandemic of severe cassava mosaic disease to Burundi. Plant Pathol 53:231.

Briddon RW, Robertson I, Markham PG, Stanley J. (2004) Occurrence of South African cassava mosaic virus (SACMV) in Zimbabwe. Plant Pathol 53:233.

Colvin J, Omongo CA, Maruthi MN, Otim-Nape GW, Thresh JM. (2004) Dual begomovirus infections and high Bemisia tabaci populations: two factors driving the spread of cassava mosaic disease pandemic. Plant Pathol 53:577-584.

Fargette D, Vié K. (1995) Simulation of the effects of host resistance, reversion and cutting selection on incidence of African Cassava Mosaic Virus and yield losses in Cassava. Phytopathology 85:370 375

Fauquet C, Fargette D. (1990) African Cassava Mosaic Virus: etiology, epidemiology, and control. Plant Dis 74:404-411.

Fondong VN, Pita JS, Rey MEC, de Kochko A, Beachy RN, Fauquet CM. (2000) Evidence of synergism between African cassava mosaic virus and a new double-recombinant geminivirus infecting cassava in Cameroon. J Gen Virol 81:287-297.

Harrisson BD, Zhou X, Otim-Nape GW, Liu Y, Robinson DJ. (1997) Role of novel type of double infection in the geminivirusinduced epidemic of severe cassava mosaic in Uganda. Ann Appl Biol 131:437-448. 
Makwarela M, Taylor NJ, Faquet CM, Rey MEC. (2006) Biolistic inoculation of cassava (Manihot esculenta Crantz) with South African cassava mosaic virus. Afr J Biotechnol 5:154-156.

Maruthi MN, Colvin J, Seal S, Gibson G, Cooper J. (2002) Co-adaptation between cassava mosaic geminiviruses and their local vector populations. Virus Res 86:71-85.

Ndunguru J, Legg JP, Aveling TAS, Thompson G, Fauquet CM. (2005) Molecular biodiversity of cassava begomoviruses in Tanzania: evolution of cassava geminiviruses in Africa and evidence of East Africa being a center of diversity of cassava geminiviruses. Virol J 2:1-23.

Ogbe FO, Atiri GI, Dixon AGO, Thottappilly G. (2003) Serological and biological variations of African cassava mosaic virus in Nigeria. Ann Appl Biol 143:203-213.

Ogbe FO, Dixon AGO, Hughes Jd'A, Alabi OJ, Okechukwu R. (2006) Status of Cassava Begomovirus and their new natural host in Nigeria. Plant Dis 90:548-553.

Olsen KM. (2004) SNPs, SSRs and inferences on cassava's origin. Plant Mol Biol 56:517-526.

Owor B, Legg JP, Okao-Okuja G, Obonyo R, Ogenga-Latigo MW. (2004) The effect of cassava mosaic geminiviruses on symptom severity, growth and root yield of a cassava mosaic virus diseasesusceptible cultivar in Uganda. Ann Appl Biol 145:331-337.

Pita JS, Fondong VN, Sangaré A, Kokora RNN, Fauquet CM. (2001) Genomic and biological diversity of the African cassava geminiviruses. Euphytica 120:115-125.
Ranomenjanahary S, Rabindran R, Robinson DJ. (2002) Occurrence of three distinct begomoviruses in cassava in Madagascar. Ann Appl Biol 140:315-318.

Ribeiro SG, Ambrozevicius LP, Avila AC et al. (2003) Distribution and genetic diversity of tomato-infecting begomoviruses in Brazil. Arch Virol 148:281-295.

Thresh JM, Cooter RJ. (2005) Strategies for controlling cassava mosaic virus disease in Africa. Plant Pathol 54:587-614.

Varma A, Malathi VG. (2003) Emerging geminivirus problem: a serious threat to crop production. Ann Appl Biol 142:145-164.

Were HK, Winter S, Maiss E. (2004) Occurrence and distribution of cassava begomoviruses in Kenya. Ann Appl Biol 145:175-184.

Zhang P, Vanderschuren H, Fütterer J, Gruissem W. (2005) Resistance to cassava mosaic disease in transgenic cassava expressing antisense RNAs targeting virus replication genes. Plant Biotechnol J 3:385-397.

Zhou X, Liu Y, Calvert L, Munoz C, Otim-Nape GW, Robinson DJ, Harrison BD. (1997) Evidence that DNA-A of a geminivirus associated with severe cassava disease in Uganda has arisen by interspecific recombination. J Gen Virol 78:2101-2111.

Zhou X, Robinson DJ, Harrison BD. (1998) Types of variation in DNA-A among isolates of East African cassava mosaic virus from Kenya, Malawi and Tanzania. Gen Virol 79:2835-2840. 